\title{
Crescimento e acúmulo de macronutrientes em chicória coberta e não coberta com polipropileno
}

\author{
Anderson Luiz Feltrim ; Arthur B Cecílio Filho ${ }^{1 ; 3}$; Bráulio Luciano A Rezende ${ }^{4}$; José Carlos Barbosa ${ }^{2}$ \\ ${ }^{1}$ UNESP-FCAV, Depto. Produção Vegetal, Via de acesso Prof. Paulo D. Castellane, s/n, 14884-900 Jaboticabal-SP; ${ }^{2}$ UNESP-FCAV, \\ Depto. Ciências Exatas; ${ }^{3}$ Bolsista CNPq; ${ }^{1}$ UNESP-FCAV, Pós-graduando; andluizfel@yahoo.com.br; rutra@fcav.unesp.br
}

\begin{abstract}
RESUMO
O experimento foi realizado com o objetivo de comparar o crescimento e acúmulo de macronutrientes pela chicória coberta e não coberta com tecido de polipropileno (TP), branco de $20 \mathrm{~g} \mathrm{~m}^{-2}$. O delineamento experimental adotado foi de blocos ao acaso em parcelas subdivididas, com 4 repetições. Na parcela, os quatro tratamentos constituíram-se de duas cultivares de chicória crespa (Chicória Crespa e AF-218) em dois sistemas de cultivo (com e sem tecido de polipropileno) e nas subparcelas as épocas de avaliação da chicória, correspondentes às idades da planta (7; 14; 21; 28; 35 e 42 dias após o transplante). A semeadura foi realizada em 02/06/03 e o transplante em 27/06/03. Foi avaliada semanalmente a altura da parte aérea, número de folhas, diâmetro das plantas, matéria fresca e seca da parte aérea e o acúmulo de macronutrientes. Exceto para o diâmetro da parte aérea, observou-se superioridade das demais características nas plantas que receberam a cobertura com TP. A cobertura com TP por todo o período pós-transplante proporcionou maior acúmulo de P, K, Mg e S. Plantas da 'AF-218' cobertas com TP por todo período pós-transplante, e que apresentaram maior matéria fresca da parte aérea, acumularam 836; 515; 205; 144; 90 e 65 mg planta ${ }^{-1}$ de $\mathrm{N}, \mathrm{K}$, Ca, Mg, S e P, respectivamente.
\end{abstract}

Palavras-chave: Cichorium endivia, análise de crescimento, agrotêxtil.

\begin{abstract}
Growth and accumulation of macronutrients on chicory, covered or not with polypropylene

The experiment was carried out to compare the growth and accumulation of macronutrients on chicory, covered or not with white polypropylene (TP), $20 \mathrm{~g} \mathrm{~m}^{-2}$ thickness. The experimental design was of randomized blocks with divided-plots in four repetitions. In the plots, the four treatments consisted of two curly endive cultivars (Crespa and AF-218) in two cultivation systems (with and without polypropylene) and the subplots consisted of the plant age $(7 ; 14$; 21; 28; 35 and 42 days after transplant). Seeds were sown on June $2^{\text {nd }}, 2003$, and transplanted on June $27^{\text {th }}$. The aerial plant part, number of leaves, diameter of plant, fresh and dry matter of the aerial part and accumulation of macronutrients were evaluated weekly. Except for the diameter of the aerial plant part, the superiority of the other characteristics on the plants covered with TP was observed. The covering of plants with TP, in all period after transplanting, resulted in a greater accumulation of $\mathrm{P}, \mathrm{K}, \mathrm{Mg}$ and S. Plants of 'AF-218' protected with TP during the whole period after transplanting and that presented greater fresh matter of the aerial part, accumulated 836; 515; 205; 144; 90 and 65 mg planta ${ }^{-1}$ of N, K, Ca, Mg, S and P, respectively.
\end{abstract}

Keyword: Endivia Cichorium, growth analysis, non-woven.

(Recebido para publicação em 19 de novembro de 2006; aceito em 18 de fevereiro de 2008)

A chicória, juntamente com alface, repolho, rúcula e couve-folha são as principais hortaliças folhosas. A chicória pode ser consumida refogada ou na forma tradicional como salada, que independente da forma de consumo constitui-se em um alimento rico em nutrientes e vitaminas.

De forma geral, nos últimos anos, têm sido observadas mudanças significativas no sistema de produção, geradas principalmente pela necessidade de melhoria da qualidade dos produtos olerícolas e obtenção da competitividade comercial. Concomitante ao cultivo tradicional a campo aberto, tem crescido a produção em ambientes protegidos, tanto com a cultura desenvolvida no solo como em hidroponia.

A produção de hortaliças em ambiente protegido permite controlar o crescimento da cultura, manipulando as condições microclimáticas.

Uma das alternativas de cultivo protegido que surgiu recentemente é o tecido de polipropileno (TP), também conhecido por agrotêxtil ou tecido não-tecido. Os primeiros relatos do uso desta técnica no Brasil se reportam a 1998, em Ponta Grossa (PR) e vem despertando cada vez mais o interesse dos olericultores.

Esta técnica consiste na colocação do TP diretamente sobre as plantas, dispensando qualquer estrutura de apoio. Esta alternativa de cultivo protegido vem atender às necessidades das hortaliças folhosas, visto que para essas culturas a viabilidade econômica de cultivos em casa de vegetação e até mesmo sob túneis é bastante questionada. Os efeitos positivos desta técnica demons- tram o incremento de produção e precocidade na colheita em algumas culturas como mandioquinha salsa (Reghin et al., 2000), pak choi (Reghin et al., 2001) e morango (Otto et al., 2000). Além da facilidade de aplicação da técnica, apresenta um menor investimento inicial, se comparado a outras estruturas de cultivo protegido.

No Brasil, esta técnica tem sido utilizada para a produção de mudas de fumo há algum tempo e os primeiros resultados com hortaliças foram avaliados na região sul do país, com a alface (Sá, 1998).

Entretanto, o tecido de polipropileno, devido à sua fragilidade, requer cuidados na hora do seu manuseio, necessitando ser removido para proceder à adubação de cobertura. Com isso, o conhecimento sobre o crescimen- 
to das espécies cultivadas permite planejar métodos racionais de cultivo, contribuindo na expressão do potencial de espécies vegetais, além de fornecer dados para a construção de modelos matemáticos descritores do crescimento. Segundo Hunt (1990), os princípios e práticas de análise do crescimento têm como objetivo descrever e interpretar o desempenho das espécies produzidas em ambiente protegido ou campo.

Do ponto de vista agronômico, a análise de crescimento e o acúmulo de nutrientes podem ser úteis no estudo do comportamento vegetal sob diferentes condições ambientais, de forma a selecionar híbridos que apresentem características desejáveis e avaliar a resposta de cultivares ao ambiente de cultivo. Permite também avaliar o crescimento final da planta como um todo e a contribuição dos diferentes órgãos no crescimento, além de auxiliar nas adubações, mediante quantificação do acúmulo de nutrientes. $\mathrm{O}$ objetivo do trabalho foi avaliar o crescimento e o acúmulo de macronutrientes pela chicória em duas condições de cultivo: coberta e não coberta com tecido de polipropileno.

\section{MATERIAL E MÉTODOS}

O experimento foi conduzido a campo, na UNESP em Jaboticabal. O solo da área, segundo Oliveira et al. (1999) é um Latossolo Vermelho Eutroférrico típico de textura muita argilosa, A moderado caulinítico-oxídico, relevo suave ondulado a ondulado.

O delineamento experimental adotado foi de blocos ao acaso, com parcelas subdivididas e quatro repetições. $\mathrm{Na}$ parcela, os tratamentos constituíram-se de duas cultivares de chicória crespa (Crespa, da ISLA Sementes e AF-218 da empresa SAKATA Seed) em dois sistemas de cultivo (com e sem tecido de polipropileno) e nas subparcelas as épocas de amostragem da chicória, correspondente às idades das plantas $(7 ; 14$; 21; 28; 35 e 42 dias após o transplante, DAT).

A semeadura foi realizada em 02/06/ 03, em bandejas de poliestireno expandido de 128 células, e substrato Plantmax $^{\circledR}$. As mudas permaneceram em ambiente protegido e foram transplan- tadas em 27/06/03, em espaçamento de 0,40 m entre linhas e 0,30 m entre plantas, com área total e útil de 3,96 $\mathrm{m}^{2} \mathrm{e}$ $1,32 \mathrm{~m}^{2}$ totalizando 39 plantas por parcela com 11 plantas úteis.

Previamente ao transplante, realizou-se análise química do solo da área experimental, que apresentou $\mathrm{pH}\left(\mathrm{CaCl}_{2}\right)$ de 5,2; $25 \mathrm{~g} \mathrm{dm}^{-3}$ de matéria orgânica, $64 \mathrm{mg} \mathrm{dm}^{-3}$ de $\mathrm{P}_{\text {(resina) }} ; 3,2 ; 30 ; 13$ e 31 $\mathrm{mmol}_{\mathrm{c}} \mathrm{dm}^{-3}$, respectivamente de $\mathrm{K}, \mathrm{Ca}$, $\mathrm{Mg}$, e $\mathrm{H}+\mathrm{Al}$, e $60 \%$ de saturação por bases do solo. Com base nesses resultados foi realizada a calagem para elevar a saturação por bases a $80 \%$. As adubações foram realizadas segundo recomendações de Trani et al. (1997) para a cultura. Para adubação de plantio, o solo recebeu $100 \mathrm{~g} \mathrm{~m}^{-2}$ do fertilizante $\mathrm{N}-\mathrm{P}_{2} \mathrm{O}_{5}$ $\mathrm{K}_{2} \mathrm{O}$ 4-30-16. Em cobertura, realizada aos 12, 23 e 33 DAT foram aplicados, por época, 2 g por planta de nitrato de amônio. Foram realizadas duas pulverizações com nitrato de cálcio a 2,5 g L ${ }^{-1}$ aos 29 e 32 DAT, para a correção da deficiência de cálcio.

O TP branco com gramatura de $20 \mathrm{~g}$ $\mathrm{m}^{-2}$ foi colocado sobre as plantas logo após o transplantio das mudas. As extremidades do TP foram fixadas com 0 próprio solo do canteiro.

Para todos os tratamentos, a colheita foi realizada em $08 / 08 / 03$, aos 42 dias após o transplantio, quando as chicórias que tiveram todo o período no campo coberto atingiram o ponto comercial. Nesta época foram comparadas todas as características avaliadas. Plantas do tratamento sem cobertura permaneceram no campo objetivando constatar o tempo adicional para que as plantas atingissem o ponto comercial (início da senescência das folhas baixeiras e folhas tenras) e pudesse ser quantificada a precocidade do tratamento coberto por todo o período.

Altura, número de folhas, diâmetro da parte aérea, massa fresca e seca da parte aérea de chicória foram avaliadas, semanalmente, a partir de sete dias após o transplante (DAT) até a colheita (42 DAT).

Previamente à obtenção da matéria seca, a parte aérea foi lavada, seca à sombra por um dia e posteriormente seca em estufa com circulação forçada de ar, a $65^{\circ} \mathrm{C}$, por 96 horas. Após, realizou-se a pesagem, moagem e a determinação das concentrações de N, P, K, Ca, Mg e $\mathrm{S}$, de acordo com Malavolta et al. (1997).

Com os dados de crescimento semanal da planta, foram obtidas as curvas de crescimento e acúmulo de nutrientes para os tratamentos, utilizando-se o modelo logístico, que obedece a seguinte equação: $\mathrm{Y}=\mathrm{a} /\left(1+e^{-\mathrm{K}(\mathrm{X}-\mathrm{Xc})}\right)$, onde: $\mathrm{a}=$ máximo valor observado, $e=$ inverso do logaritmo neperiano, $\mathrm{k}=$ taxa média de acúmulo $\mathrm{X}=$ dias após o transplante e $\mathrm{Xc}=$ máximo acumulado durante os $50 \%$ de crescimento no campo.

Os dados foram submetidos à análise de variância (Teste F), e as médias comparadas pelo teste de Tukey a 5\% de probabilidade.

\section{RESULTADOS E DISCUSSÃO}

O ciclo da chicória cultivada sob TP foi de 67 dias, dos quais 42 dias no campo, enquanto sem cobertura o ciclo foi de 75 dias, com 50 dias no campo.

Observou-se interação significativa $(p<0,01)$ dos tratamentos e idade da planta para todas as características avaliadas.

A altura de plantas diferiu entre os tratamentos desde 7 dias após o transplante (DAT) (Figura 1A). A partir dos 14 DAT, há maior altura da 'Chicória Crespa' sobre a 'AF-218', quando cultivadas sob TP. Ao final do cultivo essa diferença foi de apenas $3,28 \mathrm{~cm}$ entre as cultivares quando cultivadas sob TP. Quando não protegidas com o TP, não houve diferença significativa entre as cultivares (Figura 1A).

Entre os sistemas de cultivo, na colheita, a altura média das plantas sob proteção foi 11,4 cm maior que a média das plantas sem tecido de polipropileno (Figura 1A).

Pode-se constatar, portanto, que o emprego do TP por todo o período póstransplante da chicória proporcionou aumento na altura das plantas de ambas cultivares, diferindo, entretanto, no momento em que se manifestou essa resposta. Enquanto o TP promoveu diferença significativa para a altura de plantas da 'AF-218' aos 28 DAT, tal resposta da 'Chicória Crespa' foi constatada uma semana antes. 


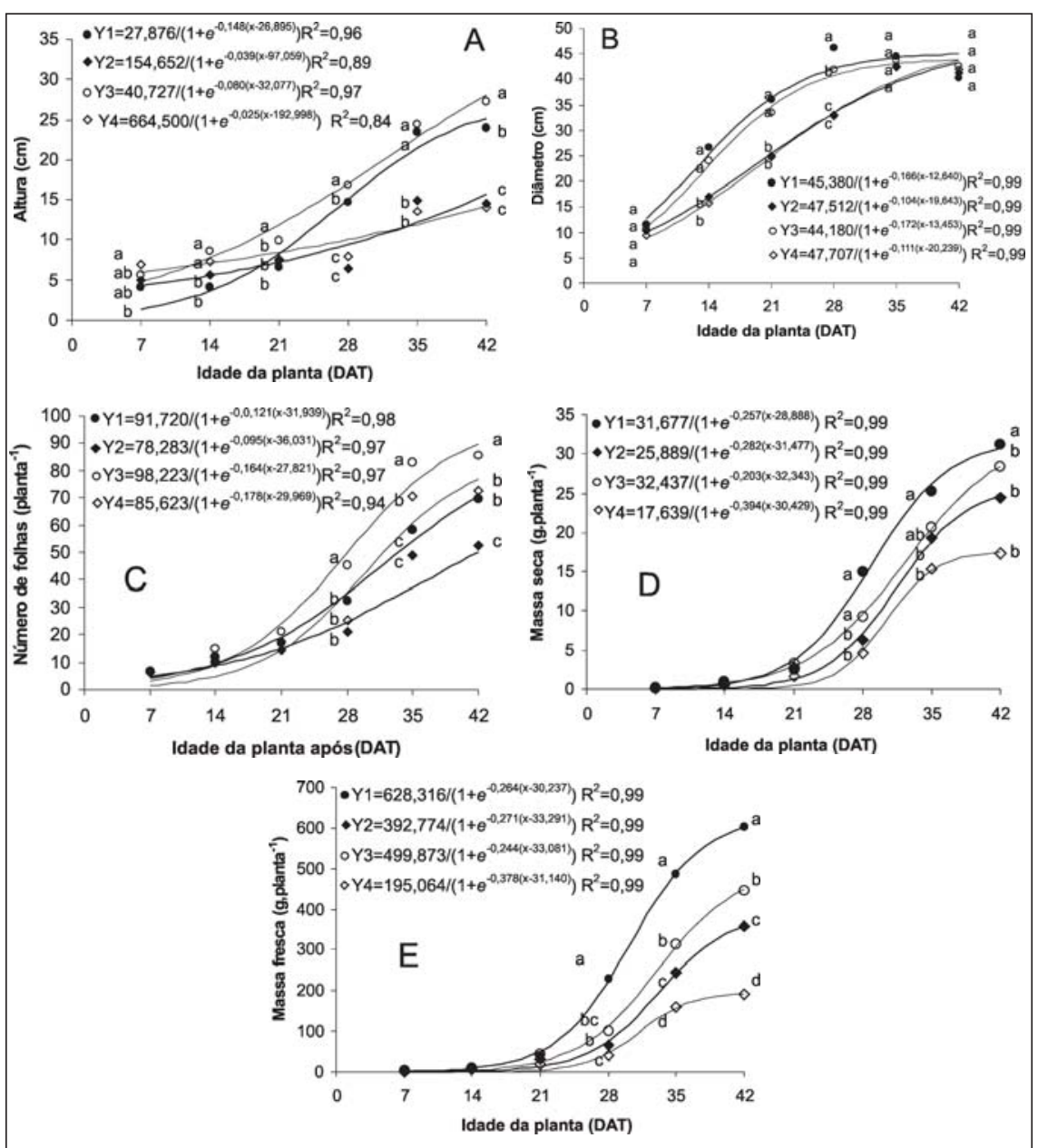

Figura 1. Altura de plantas (A), diâmetro (B), número de folhas (C), massa seca da parte aérea (D) e massa fresca da parte aérea (E), ao longo do período pós-transplante, de chicória 'AF-218' e da 'chicória crespa', cobertas ou não com tecido de polipropileno. Y1= AF-218 ciclo todo coberto, Y2=AF-218 ciclo todo descoberto, Y3=Chicória crespa ciclo todo coberto, Y4=Chicória crespa ciclo todo descoberto. Teste de Tukey a 5\% de probabilidade para diferenciar as médias em cada época de avaliação (idade da planta). Jaboticabal, UNESP-FCAV, 2003

Os maiores incrementos percentuais no diâmetro da parte aérea foram observados na primeira metade do período pós-transplante (Figura 1B). As plantas cobertas com TP atingiram os $50 \%$ do máximo diâmetro, aos 13 DAT para as duas cultivares. Para as plantas que não receberam proteção de $\mathrm{TP}$, o acúmulo dos 50\% do máximo acumulado ocorreu aos 19 DAT (Figura 1B). Muito provavelmente, a semelhança dos tratamentos para o diâmetro da parte aérea, na colheita final, possa ser devida à resposta das plantas à cobertura com TP, para altura de plantas a partir de 28 DAT. Pode-se observar que 'AF-218' e ‘Chicória Crespa’ cobertas com TP apresentam altura muito superior à das não cobertas. Tal constatação resultou, além do próprio crescimento em altura, no direcionamento das folhas de chicória para o centro da planta, uma vez que não havia mais espaço disponível entre linhas, o que concorreu para diminuir o diâmetro dessas plantas a partir dos 28 DAT.

Ao contrário do observado para altura de plantas e o diâmetro da parte aérea, o incremento médio para o número de folhas não apresentou diferença entre as plantas cobertas e descobertas com TP, para a primeira metade do período pós-transplante (21 DAT). As plantas cobertas com TP da 'AF-218' atingiram 50\% do máximo número de folhas aos 32 DAT, quatro dias antes do observado para as plantas sem cobertura. Para 'Chicória Crespa', 50\% do máximo de folhas ocorreu aos 28 e 30 DAT com e sem cobertura, respectivamente (Figura 1C).
O maior número de folhas foi observado na 'Chicória Crespa' quando cultivada com tecido de polipropileno (85,6 folhas planta'-1). Para 'AF-218', o cultivo protegido por TP também proporcionou maior número de folhas $(69,3)$ por planta do que não coberto com TP (52,5 folhas planta-1) (Figura 1C).

A massa seca da parte aérea (MSPA) acumulada na primeira metade do período pós-transplante foi de aproximadamente $10 \%$ do total, independente do tratamento. Plantas de ‘AF-218' cobertas com TP atingiram 50\% do máximo de MSPA aos 29 DAT e aos 32 DAT para 'Chicória Crespa'. Para as plantas não cobertas com TP, 50\% do máximo acumulado de MSPA ocorreu aos 31 DAT para a 'AF-218' e aos 30 DAT para a 'Chicória Crespa' (Figura 1D).

A maior massa fresca foi obtida com a 'AF-218' coberta com tecido de polipropileno (603 g planta-1). A 'Chicória Crespa’ também coberta com TP apresentou elevada massa fresca (447 g planta $\left.{ }^{-1}\right)$, porém inferior à observada na 'AF-218' em 35\%, aproximadamente. Os piores desempenhos da chicória foram obtidos sem a cobertura com polipropileno. A massa fresca da chicória 'AF-218' coberta com TP superou em $69 \%$ e em $216 \%$ as massas verificadas respectivamente para 'AF218' e 'Chicória Crespa' sem cobertura (Figura 1E).

Verifica-se que maiores altura e número de folhas da 'Chicória Crespa' não proporcionaram maior massa fresca da parte aérea (MFPA), provavelmente resultante de diferenças morfológicas foliares. Enquanto a 'AF-218' apresenta limbo foliar mais largo desde a região próxima à base do pecíolo, a 'Chicória Crespa' possui limbo mais estreito e repicado, que se alarga a partir de um terço do comprimento foliar, resultando em menores massas seca e fresca da parte aérea.

As plantas cobertas com TP atingiram 50\% do máximo acumulado em MFPA, aos 30 DAT para a 'AF-218' e 33 DAT para a 'Chicória Crespa’. Plantas não cobertas com TP, acumularam 50\% do máximo de MFPA aos 33 e 31 DAT respectivamente para a 'AF-218' e ‘Chicória Crespa’ (Figura 1E). 
O acúmulo de MFPA de plantas cobertas com TP na primeira metade do período após o transplante foi de, aproximadamente, $7 \%$ para a 'AF-218' e 10\% para 'Chicória Crespa'. Para as plantas que não receberam a cobertura, o acúmulo foi de 8 e $9 \%$, respectivamente. Isto significa que mais de $90 \%$ da MFPA e MSPA foram acumulados na segunda metade do período após o transplante (Figuras 1D e 1E).

Esse maior crescimento das plantas cultivadas sob cobertura de polipropileno está relacionado com os valores de temperaturas máximas e mínimas do ar na superfície do solo. Constatou-se que sob cobertura de polipropileno, as temperaturas máximas e mínimas do ar na superfície do solo foram, respectivamente, maiores e menores do que as observadas em solo sob cultivo sem cobertura com polipropileno. Em média, os valores das temperaturas máximas e mínimas na superfície do solo das plantas que receberam a cobertura com polipropileno foram respectivamente, inferiores em $2^{\circ} \mathrm{C}\left(32,7-30,7^{\circ} \mathrm{C}\right)$ e superiores em $1,9^{\circ} \mathrm{C}$ $\left(10,6-8,7^{\circ} \mathrm{C}\right)$, à condição em que não utilizou-se a cobertura de polipropileno. Uma das razões desses resultados está relacionado, possivelmente, com a formação de uma película de água condensada que se forma no interior do polipropileno, impedindo a emissão da radiação de onda longa para o ambiente externo durante a noite, uma vez que, segundo Gregoire (1989), a água é praticamente impermeável à radiação de onda longa.

A quantidade de macronutrientes foi influenciada significativamente pela interação dos fatores avaliados.

$\mathrm{O}$ acúmulo de $\mathrm{N}$ pela chicória ao longo do período pós-transplante mostrou-se muito pequeno até 21 DAT para todos os tratamentos. Para a 'AF-218' cultivado sob (TP), o acúmulo de $\mathrm{N}$ na metade do período em campo (21 DAT) correspondeu a aproximadamente 5\% do total acumulado na colheita final, 42 DAT (Figura 2A).

No período seguinte, de 21 a 35 DAT, para ambas as cultivares, com e sem TP, foram constatados os maiores acúmulos de N pela planta. 'AF-218' coberto com TP acumulou neste perío-
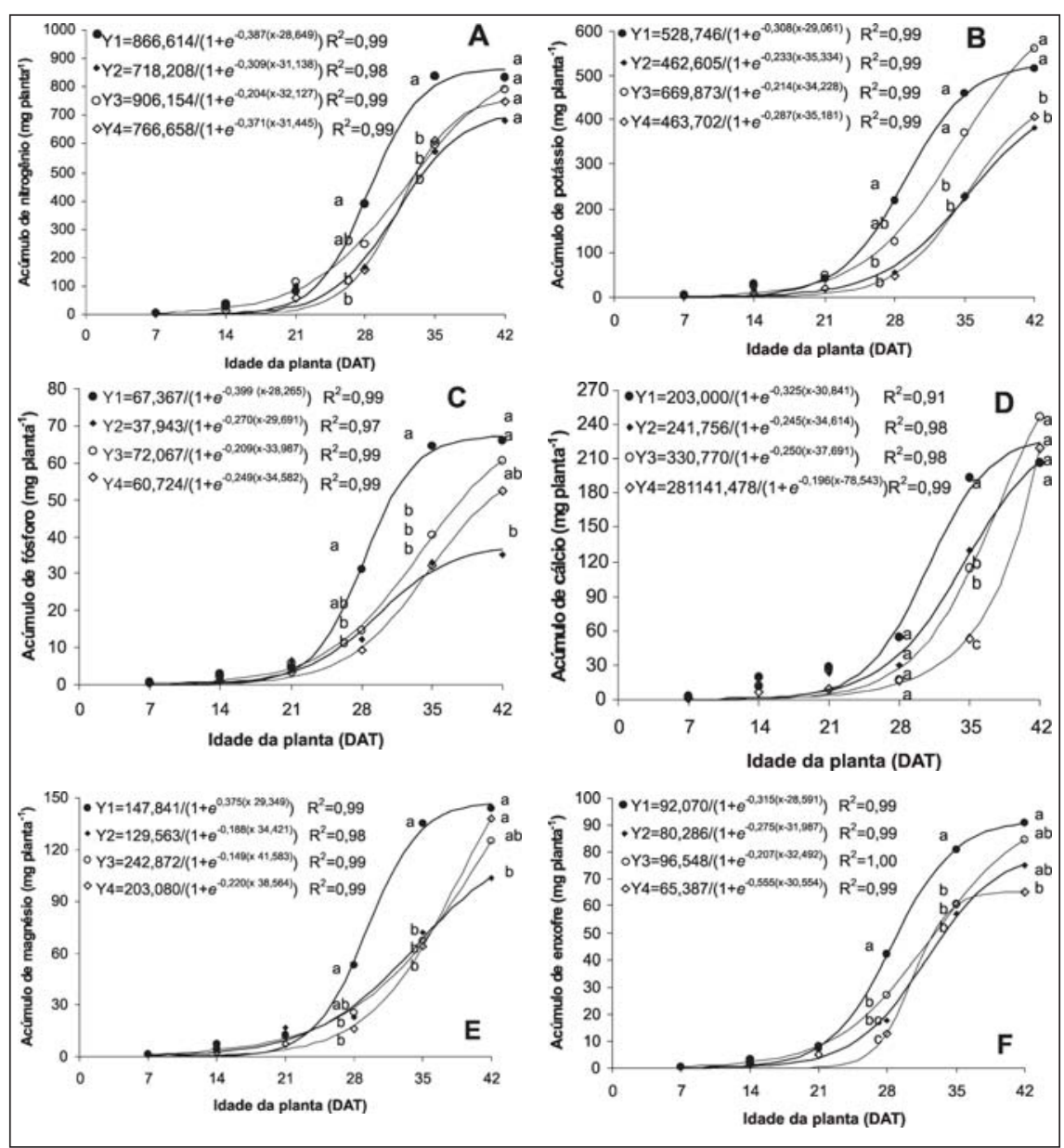

Figura 2. Acúmulo de nitrogênio (A), potássio (B), fósforo (C), cálcio (D), magnésio (E) e enxofre (F) na parte aérea, ao longo do período pós-transplante, de chicória 'AF-218' e da 'Chicória Crespa', cobertas ou não com tecido de polipropileno. Y1= AF-218 ciclo todo coberto, Y2=AF-218 ciclo todo descoberto, Y3=Chicória crespa ciclo todo coberto, Y4=Chicória crespa ciclo todo descoberto. Teste de Tukey a 5\% de probabilidade para diferenciar as médias em cada época de avaliação (idade da planta). Jaboticabal, UNESP-FCAV, 2003.

do $758 \mathrm{mg}$ planta $^{-1}$, o que correspondeu a aproximadamente $88 \%$ do total acumulado (Figura 2A). Na cultura da alface, Garcia et al. (1982a) também verificam que o acúmulo de nutrientes nas primeiras três semanas foi lento, aumentando rapidamente após este período. Aos 21 DAT o acúmulo de N para alface foi aproximadamente de $38 \%$.

A marcha de acúmulo de $\mathrm{N}$ pela chicória, independente do tratamento apresentou um terceiro período, com características bem distintas do primeiro $(0 \mathrm{a}$ 21 DAT) e segundo (21 a 35 DAT) períodos. Na etapa final do período póstransplante, o acúmulo de $\mathrm{N}$ foi bastante reduzido, especialmente para 'AF218' coberta com TP, que apresentou, nestes últimos 7 dias, taxa de acúmulo de aproximadamente $8 \mathrm{mg}$ planta $\mathrm{dia}^{-1}$ de $\mathrm{N}$, muito menor que o incremento de
$54 \mathrm{mg}$ planta $^{-1}$ dia $^{-1}$ verificado no período anterior, de 21 a 35 DAT (Figura 2A).

Conforme observado por Katayma (1993), na cultura da alface, o crescimento e o acúmulo de nutrientes foram lentos até 30 dias após a emergência, aumentando rapidamente após esse período. Esse autor ressaltou que apesar da alface absorver quantidades relativamente pequenas de nutrientes, quando comparadas a outras culturas, é considerada cultura exigente em nutrientes devido ao seu ciclo curto (2 a 3 meses), principalmente na fase final do seu ciclo. Grangeiro et al. (2006) também observaram lento crescimento para alface no inicio do cultivo e os maiores acúmulos de nutrientes e massa seca na última semana. Além disso, deve-se considerar que as adubações para a chicória e o almeirão seguem a recomenda- 
Tabela 1. Idade da planta (DAT) em que ocorreu 50\% do acúmulo máximo de nutrientes de dois cultivares de chicória com e sem cobertura de polipropileno (TP). Jaboticabal, UNESPFCAV, 2003.

\begin{tabular}{lclcccc}
\hline \multirow{2}{*}{ Tratamentos } & $\mathbf{N}$ & $\mathbf{P}$ & $\mathbf{K}$ & $\mathbf{C a}$ & $\mathbf{M g}$ & $\mathbf{S}$ \\
\cline { 2 - 7 } & \multicolumn{6}{l}{ Dias após o transplantio (DAT) } \\
\hline 'AF-218' com TP & 29 & 28 & 29 & 31 & 29 & 29 \\
'AF-218' semTP & 31 & 30 & 35 & 35 & 34 & 32 \\
'Chicória Crespa' com TP & 32 & 34 & 34 & 37 & 41 & 32 \\
'Chicória Crespa' sem TP & 31 & 35 & 35 & 78 & 38 & 31 \\
\hline
\end{tabular}

ção da alface, além de não existir recomendações específicas para diferentes ambientes de cultivo. Esses fatos são muito importantes para melhor compreensão do manejo da adubação da cultura.

O nitrogênio entre todos os nutrientes absorvidos é, em geral, o que promove maior incremento na produtividade das culturas. Em alface, a totalidade ou quase desse elemento deve ser utilizada em coberturas nitrogenadas, considerando que cerca de $62 \%$ do total extraído é absorvido na segunda metade do período após o transplante (Garcia et al., 1982b). Para a chicória parece não ser diferente, pois cerca de $95 \%$ do $\mathrm{N}$ acumulado pela chicória ocorreu na segunda metade do período pós-transplante (Figura 2A).

$\mathrm{O}$ maior acúmulo de $\mathrm{N}$ do que de $\mathrm{K}$ pela chicória difere dos resultados verificados para alface, que apresenta maior quantidade de K (Fernandes et al. 1981; Garcia et al., 1982a, b; Faquin et al., 1996; Furlani et al., 1999). Também em chicória, Furlani et al. (1999) observaram maior acúmulo de $\mathrm{K}$ do que de $\mathrm{N}$.

Até 21 DAT, o acúmulo de K representou somente $8 \%$ do total acumulado, alcançando $80 \%$ no final do segundo período (Figura 2B). A taxa de acúmulo diário de $\mathrm{K}$ foi de 1,9; 29,6 e 9 mg planta ${ }^{-1}$, respectivamente para o primeiro (0 a 21 DAT) segundo (21 a 35 DAT) e terceiro (35 a 42 DAT) períodos. Semelhante ao observado para N, o acúmulo de K para 'AF-218' coberto com TP reduziu significativamente no terceiro período, enquanto para a mesma cultivar sem cobertura e para a 'Chicória Crespa', independente do sistema de cultivo, o acúmulo de $\mathrm{K}$ ainda mostrou-se com elevada taxa diária de incremento.

Para a alface, chicória e almeirão, praticamente a totalidade desse elemen- to é aplicada em adubações de base ou em pré-transplante. Entretanto, deve-se considerar que a chicória acumulou cerca de $92 \%$ do total de $\mathrm{K}$ na segunda metade do período após o transplante. Para a cultura da alface, Garcia et al. (1982 a e b) observaram cerca de 62\% para o mesmo período. Desse modo, adubações em cobertura para o K, dependendo do clima e/ou solo podem proporcionar aumento na eficiência do aproveitamento do K aplicado e, conseqüentemente, na produtividade da cultura da chicória.

Como observado anteriormente para o $\mathrm{N}$ e K, o fósforo também foi mais extraído (95\%) na segunda metade do ciclo (Figura 2C). Na cultura da alface, o $P$ é o quarto nutriente mais exigido, sendo mais de $67 \%$ extraído na segunda metade do período após o transplante (Garcia et al., 1982 a e b ).

Observou-se sintoma de deficiência de cálcio em todos os tratamentos, caracterizado pela necrose das margens das folhas da chicória. Essa anormalidade fisiológica de ordem nutricional é conhecida como queimas dos bordos ou "tipburn".

O acúmulo de cálcio (Ca) não diferiu entre os tratamentos na colheita. Provavelmente, as pulverizações foliares com nitrato de cálcio a $2,5 \mathrm{~g} \mathrm{~L}^{-1}$ para a correção da deficiência, constatada a partir de 29 DAT pode ter favorecido a não distinção entre os tratamentos quanto ao acúmulo de N e Ca (Figura 2A e D).

Como pode-se observar na Tabela 1 , as plantas da 'AF-218' cobertas com TP atingiram $50 \%$ do máximo acumulado antecipadamente em relação às plantas sem cobertura, para todos os macronutrientes. Entretanto, para as plantas de 'Chicória Crespa' cobertas com TP somente foi observado precocidade no acúmulo para o $\mathrm{K}$, $\mathrm{P}$ e o Ca
(Figuras 2 B, C e D respectivamente).

Em média, as plantas de 'AF-218' cobertas com TP atingiram $50 \%$ do máximo acumulado aproximadamente seis dias antes das plantas de 'Chicória Crespa' cobertas. Em relação às plantas de 'AF-218' descobertas, somente o P (Figura 2C) e Mg (Figura 2E) atingiram antecipadamente $50 \%$ do máximo acumulado (Tabela 1). Para o S (Figura 2F) houve um atraso em 1 dia, N (Figura 2A) e K (Figura 2B) ocorreu simultaneamente (Tabela 1).

Considerando que N e K são usados em cobertura, a precocidade de 3 e 7 dias para que 'AF-218' coberto com TP acumulasse $50 \%$ da quantidade máxima de $\mathrm{N}$ e K demonstra a necessidade de considerar os diferentes sistemas de produção (ambiente e cultivar) como fator modificador da época a ser realizada a adubação de cobertura. Para esses nutrientes as épocas dos 50\% do máximo acumulado encontram-se entre 29 e 31 para o N e para o K entre 29 e 35 DAT, época em que a MSPA também apresentou elevado incremento (Tabela 1 e Figura 1D).

As marchas de acúmulo de nutrientes observadas para 'AF-218', cultivada sob o TP por todo o período póstransplante, condição que proporcionou maior massa fresca, precocidade e qualidade visual da parte aérea, permitiram constatar que a seqüência decrescente de macronutrientes acumulados foi $\mathrm{N}$, $\mathrm{K}, \mathrm{Ca}, \mathrm{Mg}$, S e P, com respectivamente 862, 519, 224, 146, 90 e 67 mg planta $^{-1}$. Considerando uma população de 83.333 plantas $\mathrm{ha}^{-1}$, a quantidade acumulada para 'AF-218' foi de aproximadamente 71,8, 5,6, 43,2, 18,6, 12,2 e 7,5 $\mathrm{kg} \mathrm{ha}^{-1}$, respectivamente de $\mathrm{N}, \mathrm{P}, \mathrm{K}, \mathrm{Ca}, \mathrm{Mg}$ e $S$, enquanto sem cobertura, para a mesma cultivar (AF-218) as quantidades foram 57,$8 ; 2,9 ; 31,7 ; 17,2 ; 8,6$; e 6,2 $\mathrm{kg} \mathrm{ha}^{-1}$ de N, P, K, Ca, Mg e S, respectivamente.

Para a 'Chicória Crespa', sem cobertura com TP, que teve a menor MFPA de chicória, entre os tratamentos avaliados, o acúmulo de N, P, K, Ca, Mg e $\mathrm{S}$ foi, respectivamente, de 62,$5 ; 4,3$; 33,$8 ; 18,2 ; 11,5$ e $5,4 \mathrm{~kg} \mathrm{ha}^{-1}$.

Assim como ocorre com a maioria das espécies, alface (Grangeiro et al., 2006), melão (Silva Junior et al., 2006), 
beterraba (Grangeiro et al., 2007), melancia (Grangeiro \& Cecílio Filho, 2005), minitubérculos de batata (Favoreto, 2005), tomate (Fayad et al., 2000), o acúmulo de nutrientes seguiu o mesmo comportamento das características de crescimento, ou seja, os períodos de maior acúmulo de nutrientes coincidiram com o maior acúmulo de MSPA e MFPA, independente da cobertura utilizada.

O uso do polipropileno como cobertura das plantas de chicória proporcionou maior crescimento em altura, número de folhas, massa seca e fresca da parte aérea, independente da cultivar. A cultivar AF-218 com cobertura de polipropileno apresentou maior crescimento que a cultivar Chicória Crespa.

\section{REFERÊNCIAS}

CAMARGO MN; KAUFFMAN JH. 1987. Classificação de solos usada em laboratórios pedológicos no Brasil. Boletim Informativo da Sociedade Brasileira Ciência do Solo 12: 1133.

CENTURION JF. 1998. Características e classificação dos solos da Faculdade de Ciências Agrárias e Veterinárias de Jaboticabal. Jaboticabal: UNESP. 84p (Tese).

FAVORETTO P. 2005. Parâmetros de crescimento e marcha de absorção de nutrientes na produção de minituberculos de batata $\mathrm{cv}$. Atlantic. Piracicaba: ESALQ. 98p. (Tese mestrado).

FAYAD JA; MONDARDO M; OLIVEIRA SO. 2000. Absorção de nutrientes, crescimento e produção de tomate, cultivado no sistema de plantio direto. Boletim técnico. EPAGRI. 2: 14p.
FAQUIN V; FURLANI NETO AE; VILELA LAA. 1996. Produção de alface em hidroponia. Lavras: UFLA. 50p.

FERNANDES PD; OLIVEIRA GD; HAAG HP. 1981. Absorção de macronutrientes pela cultura da alface. In: HAAG HP; MINAMI K. Nutrição e mineral de hortaliças. Campinas: Fundação Cargil. p.143-151.

FURLANI PR; BOLONHEZI D; SILVEIRA LCP; FAQUIN V. 1999. Nutrição mineral de hortaliças, preparo e manejo de soluções nutritivas. Informe Agropecuário 20: 90-98.

GARCIA LLC; HAAG HP; MINAMI K; DECHEN AR. 1982a. Nutrição mineral de hortaliças. Concentração e acúmulo de macronutrientes pela alface (Lactuca sativa L.) cv. Brasil 48 e clausess Aurélia. In: Anais da Escola Superior de Agricultura ''Luiz de Queiroz”, XLIX. Anais... Piracicaba: 39: 455-484.

GARCIA LLC; HAAG HP; MINAMI K; DECHEN AR. 1982b. Nutrição mineral de hortaliças. Concentração e acúmulo de macronutrientes pela alface (Lactuca sativa L.) cv. Brasil 48 e clausess Aurélia. Anais da Escola Superior de Agricultura '’Luiz de Queiroz”, XL. Anais... Piracicaba: 39: 455-484.

GRANGEIRO LC; COSTA KR; MEDEIROS MA; SALVIANO MZ; BEZARRA NETO F; OLIVEIRA SL. 2006. Acúmulo de nutrientes por três cultivares de alface cultivadas em condições do Semi-Árido. Horticultura brasileira 24: 190-194.

GRANGEIRO LC; NEGREIROS MZ; SOUZA BS; AZEVÊDO PE; OLIVEIRA SL; MEDEIROS MA. 2007. Acúmulo e exportação de nutrientes em beterraba. Ciencia e Agrotecnologia 31: 267-273.

GREGOIRE P. 1989. Los no tejidos y la protección de los productos hortícolas. Horticultura, Mendoza, 44: 61-64.

HUNT R. 1990. Basic growth analysis. London. Unwin Hyman. 112 p.

KATAYMA M. 1993. Nutrição e adubação de alface, chicória e almeirão. In: FERREIRA ME; CASTELANE PD; CRUZ MCP. Nutrição e adubação de hortaliças. Piracicaba: POTAFOS. p.141-147.
MALAVOLTA E; VITTI GC; OLIVEIRA SA. 1997. Avaliação do estado nutricional das plantas: princípios e aplicações. Piracicaba: POTAFOS. 201p.

OLIVEIRA JB; CAMARGO MN; ROSSI M; CALDERANO FILHO B. 1999. Mapas pedológicos do Estado de São Paulo: legenda expandida. Campinas: EMBRAPA Solos. 63p.

OTTO RF; REGHIN MY; TIMÓTEO P; PEREIRA AV; MADUREIRA A. 2000. Resposta produtiva de duas cultivares de morango cultivadas sob "não tecido" de polipropileno no município de Ponta Grossa PR. Horticultura brasileira 18: 210-211.

REGHIN MY; OTTO RF; SILVA JBC. 2000. "'Stimulate Mo" e proteção com 'não tecido" no pré-enraizamento de mudas de mandioquinha-salsa. Horticultura brasileira 18: 53-57.

REGHIN MY; OTTO RF; DALLA PRIA M; FELTRIN AL; VINNE J. 2001. Cobertura do solo e proteção das plantas de pak choi cultivadas com 'não tecido" de polipropileno no período da primavera. In: CONGRESSO BRASILEIRO DE OLERICULTURA, 41. Resumos... Brasília: SOB (CD-Rom)

SÁ GD. 1998. Efeito da proteção com 'Não Tecido" sobre o desenvolvimento e produção da alface (Lactuca sativa L.). Ponta Grossa: UEPG. 31 f. (Monografia graduação).

SILVA JÚNIOR MJ; MEDEIROS JF; OLIVEIRA FHT; DUTRA I. 2005. Acúmulo de matéria seca e absorção de nutrientes pelo meloeiro "pele-de-sapo" Engenharia Agrícola e Ambiental 10: 364-368.

GRANGEIRO LC; CECÍLIO FILHO AB. 2005. Acúmulo e exportação de nutrientes em melancia sem sementes. Horticultura Brasileira 23 763-767.

TRANI PE; AZEVEDO FILHO JA. 1996. Alface, almeirão, chicória, escarola, rúcula e agrião d'água. In: RAIJ, B. van. In: Recomendação de adubação e calagem para o Estado de São Paulo. (Boletim Técnico, 100). Campinas: IAC 168p. 